\title{
Diagnosing Vascular Dementia by Skin Biopsy - Uniqueness of CADASIL
}

\author{
Saara Tikka ${ }^{1}$, Kati Mykkänen², Maija Junna², Robert Bergholm³, \\ Minna Pöyhönen ${ }^{3}$, Marc Baumann ${ }^{3}$, Matti Viitanen ${ }^{2}$ and Hannu Kalimo ${ }^{3}$ \\ ${ }^{1}$ Harvard Medical School, \\ 2University of Turku, \\ ${ }^{3}$ University of Helsinki, \\ 1 USA \\ 2,3Finland
}

\section{Introduction}

Cerebral autosomal dominant arteriopathy with subcortical infarcts and leukoencephalopathy (CADASIL) is the most common hereditary subcortical vascular dementia. CADASIL is caused by mutations in NOTCH3 gene, which encodes a large transmembrane receptor NOTCH3. The key pathological finding is the accumulation of granular osmiophilic material (GOM), which contains extracellular domains of NOTCH3, on degenerating vascular smooth muscle cells (VSMCs). CADASIL is usually suspected on the basis of patient's clinical picture, relatively characteristic findings in brain MRI and information on family history. Definite diagnosis can be established by molecular genetic detection of a pathogenic mutation in NOTCH3 gene. The gene analysis may, however, be laborious, due to the high number of different pathogenic mutations (over 200 at present) and besides, comprehensive genetic analyses are available only in few genetic laboratories. However, CADASIL is a unique dementing disorder, because it is also possible to diagnose it at a high level of certainty by a skin biopsy using electron microscopic (EM) or immunohistochemical (IHC) analysis of dermal arteries.

\section{CADASIL}

\subsection{Epidemiology}

CADASIL, the most common hereditary vascular dementia, is characterized by migraineous headache with aura, recurrent ischemic attacks, cognitive decline and psychiatric symptoms as the four main features. Migraneous headache with aura occurs in about one third of patients and it may begin already before the age of 10 years (Kalimo et al., 2008). The age at first ever stroke varies widely, usually from 25 to 65 years [yet, the youngest patient who has suffered from a stroke was 11 years-of-age (Granild-Jensen et al., 2009)].

\subsection{Etiology}

CADASIL is caused by mutations in NOTCH3 gene encoding a transmembrane receptor NOTCH3 (Joutel et al., 1996). Virtually all pathogenic mutations lead to an odd number of 
cysteine residues in one of the 34 epidermal growth factor (EGF) like repeats in the extracellular domain of NOTCH3 (N3ECD). The mutations result in degeneration of vascular smooth muscle cells (VSMC), in which NOTCH3 is predominantly expressed in adult humans (Joutel et al., 2000). The main pathological findings are accumulation of N3ECD on degenerating VSMCs as well as fibrosis and thickening of arterial walls, stenosis of arterioles and lacunar infarcts (Miao et al., 2004, Ruchoux et al., 1995). In electron microscopy (EM) the pathognomonic feature of CADASIL is accumulation of granular osmiophilic material (GOM) in indentations of the VSMCs or in the extracellular space in close vicinity to VSMCs (Baudrimont et al., 1993, Ruchoux et al., 1995). The exact composition of GOM has not been elaborated, but an immunogold EM study suggested N3ECD to be a component of GOM (Ishiko et al., 2006).
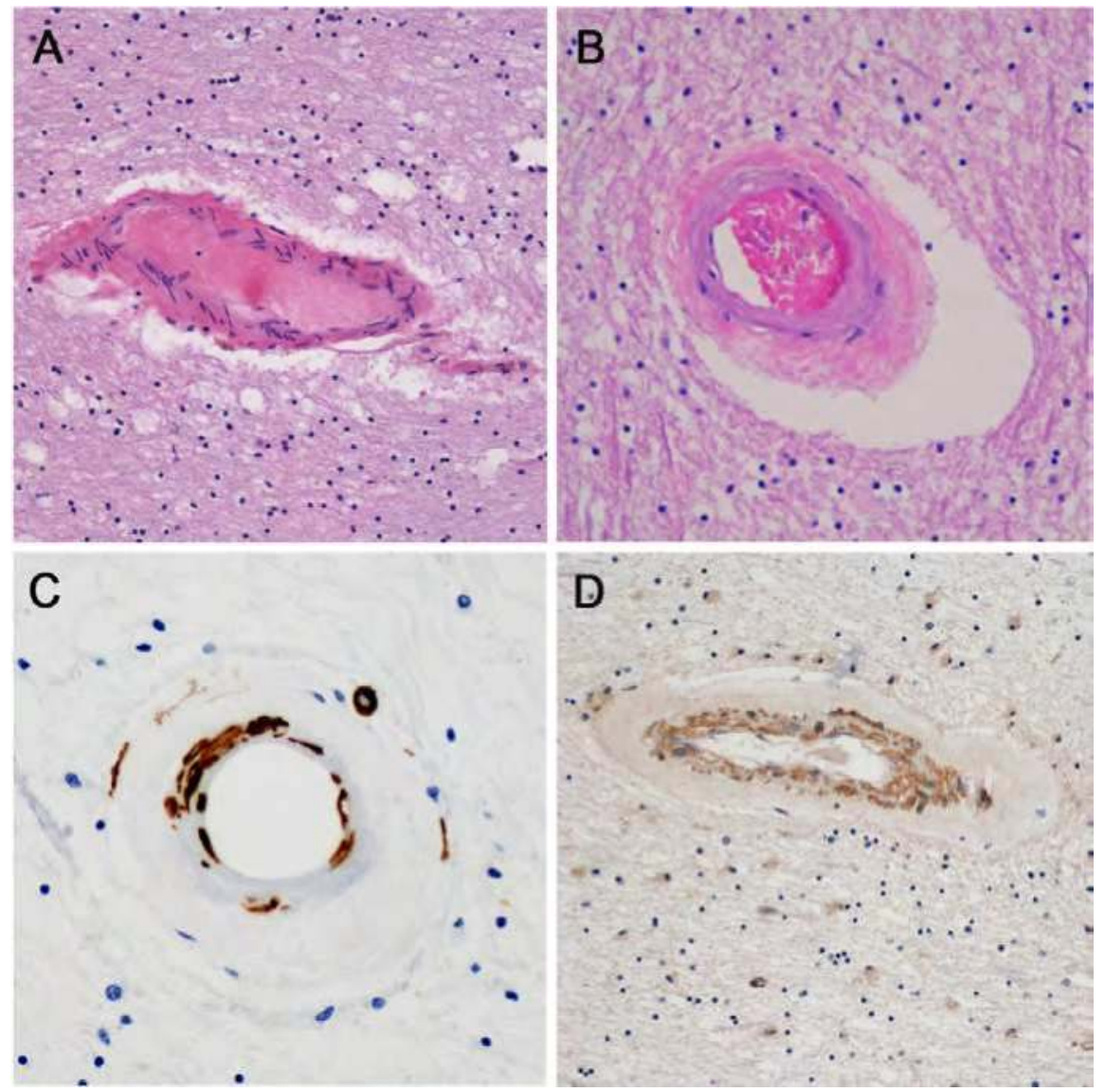

Fig. 1. Histopathological findings in CADASIL brain arteries. A) Small arteriole from the cerebral white matter of a control person. H\&E staining. B) Corresponding arteriole from a CADASIL patient. Note the marked thickening of the wall. H\&E staining. C) Degeneration of VSMCs is seen as decreased immunoreactivity for $\alpha$-SMA. D) N3ECD has accumulated in the tunica media of an affected arteriole. 


\subsection{Vascular pathology \\ 2.3.1 Brain arteries}

Pathological changes are present in all small to medium-sized arteries of the body and in some veins and capillaries. In small arterioles in cerebral white matter (WM) histological stainings reveal markedly thickened walls with accumulation of N3ECD in the degenerating tunica media. This material is basophilic in H\&E (Figure 1A and B) and red in PAS stainings. Decreased immunopositivity for $\alpha$-smooth muscle actin ( $\alpha$-SMA) reveals degeneration of the VSMCs (Figure 1C). The accumulation of N3ECD can be verified by immunohistochemical staining (Figure 1D). Accumulation of extracellular matrix proteins, including various types of collagens and fibronectin and vimentin outside the degenerating VSMCs causes the thickening of the vessel walls (Figures 1A-D). On the basis of the stainings above CADASIL can be distinguished from the two other arteriopathies with thickened walls: In arteriolosclerosis (Binswanger disease) and cerebral amyloid angiopathy the walls are homogeneously stained, either like collagen or like amyloid. The brain arteries are usually not studied until post mortem, when the degeneration of VSMCs and the accumulation of GOM are already obvious at the LM level. Thus, EM examination is not needed and is usually not performed.

\subsubsection{Dermal arterioles - appearance of GOM}

Skin biopsies are most often performed and the specimens examined at earlier stages of CADASIL, often when the diagnosis is only suspected. In histological sections the skin usually looks relatively normal: the possible thickening of the walls of small arteries within the dermal connective tissue is difficult to discern. Thus, either EM or IHC examination is needed.

EM analysis of an arterial wall reveals enlarged subendothelial space and the degenerating VSMCs which appear irregularly shaped as they have lost their intercellular connections (Figure 2; Ruchoux and Maurage, 1997, Kalimo et al., 2008). As a striking and pathognomonic feature of CADASIL, GOM accumulates on VSMCs (Baudrimont et al., 1993, Ruchoux et al., 1995). Already before the gene defect was found, GOM was detected in skin biopsies from CADASIL patients (Ruchoux et al., 1994). So far GOM has not been described in any other disease entity: GOM is negative in both histological (e.g. Congo red and thioflavin) and immunohistochemical stainings for different amyloid angiopathies (Ragno et al., 1995, Ruchoux and Maurage, 1997). GOM accumulates in the arterial wall, in the tunica media and is usually detected in the close vicinity to VSMCs, often in small indentations of VSMC plasma membrane within the basal lamina (Figures 2 and 3A), which is usually irregularly thickened, or GOM lies free in the extracellular space (Figures 2 and 6C.). The indentations are often associated with caveolar structures (Figure 3A), but as caveolae are common structures of VSMCs, their pathogenetic significance is unclear. The size of GOM deposits is variable, ranging from $0.2 \mu \mathrm{m}$ to $0.8 \mu \mathrm{m}$, and they are composed of 10-15 nm granules (Ruchoux and Maurage, 1997). GOM appears in EM as evenly electron dense or, as often, denser on the side which is towards the VSMC membrane (Figure 3A). The exact composition of GOM has not been fully clarified, but N3ECD is a component of GOM as demonstrated by immunoelectron microscopy (Ishiko et al., 2006). Moreover, with confocal microscopy, N3ECD immunoreactivity can be seen as dot-like accumulations on the arterial wall, in concordance with the appearance of GOM deposits in the EM (Figure 3B). The degeneration of VSMCs and the accumulation of GOM begin early and the morphological changes in arteries and the accumulation of GOM are already detectable before the age of 20 (Tikka et al., 2009)( Figure 3C ). 


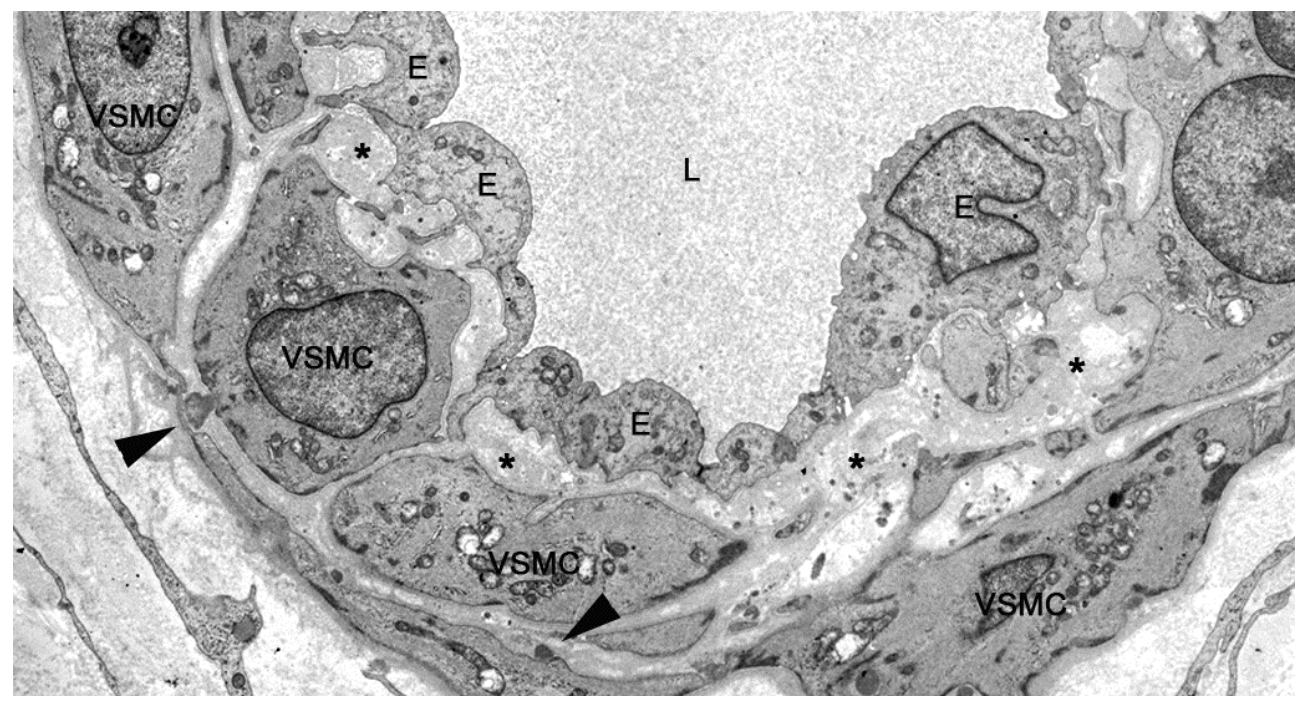

Fig. 2. EM micrograph of a dermal artery from a CADASIL patient. Characteristic vascular pathology is clearly detectable already in early age. Subendothelial space is widened (asterisks) and VSMCs are irregularly shaped and have lost their intercellular connections. Accumulation of GOM is seen in close vicinity of VSMCs. CADASIL patient with pArg133Cys mutation. $\mathrm{L}=$ arterial lumen, $\mathrm{E}=$ endothelial cell, VSMC=vascular smooth muscle cell. Two GOMs are pointed with arrowheads. Figure is reproduced with permission from Future Neurology (Kalimo et al., 2008)
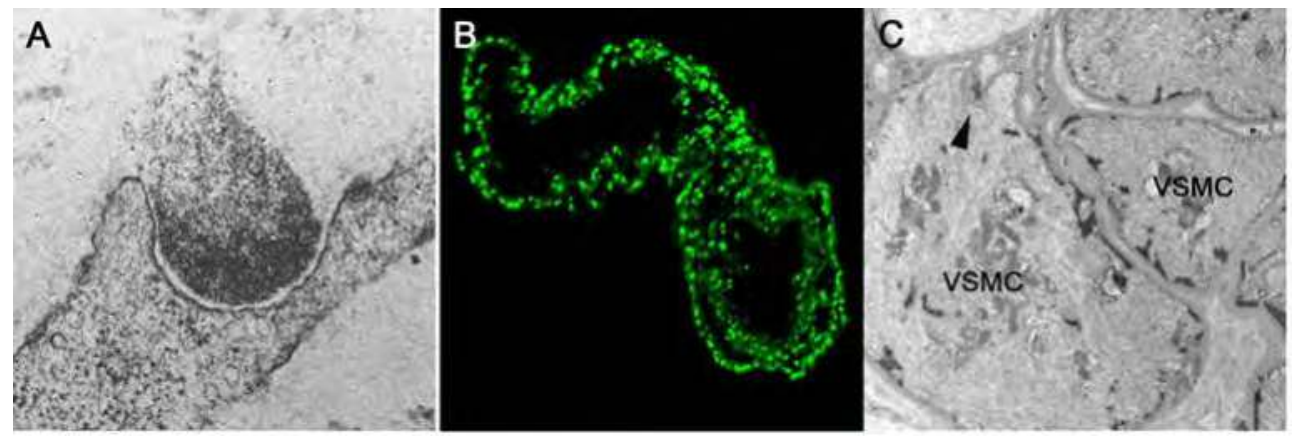

Fig. 3. Dermal artery of CADASIL patient. A) EM micrograph of CADASIL patient (p.Arg133C) showing characteristic GOM deposits in the intendation of VSMC with caveolar structures. B) Confocal microscopy reveals N3ECD immunoreactivity as dot-like accumulations in the arterial wall in concordance with GOM deposits. A 62 year-old patient carrying p.Tyr1069Cys mutation. C) Accumulation of GOM in an artery of 19 year-old CADASIL patient with mutation p.Arg133Cys. Figure B is reproduced with permission from Future Neurology (Kalimo et al., 2008) 


\section{Diagnosis of CADASIL}

\subsection{Clinical findings}

CADASIL is suspected in patients with the typical clinical features, occasionally with positive family history. Patients are sometimes hypertensive, but it does not have any diagnostic significance. White matter alterations in brain T2-weighted MRI (O'Sullivan et al., 2001) are important clues. In T2w MRI an experienced radiologist can detect changes that are highly suggestive of CADASIL already in asymptomatic carriers of the gene defect (even before the age of 20). Hyperintensities on T2w and FLAIR MRI in temporopolar WM are nearly diagnostic of CADASIL (Figures 4A). In addition, cerebral periventricular WM and capsula externa hyperintensities are characteristic (Figure 4B; Chabriat et al., 1998). Laboratory examinations are usually non-rewarding or non-specific, i.e. the examinations may reveal risk factors of other cerebrovascular diseases.
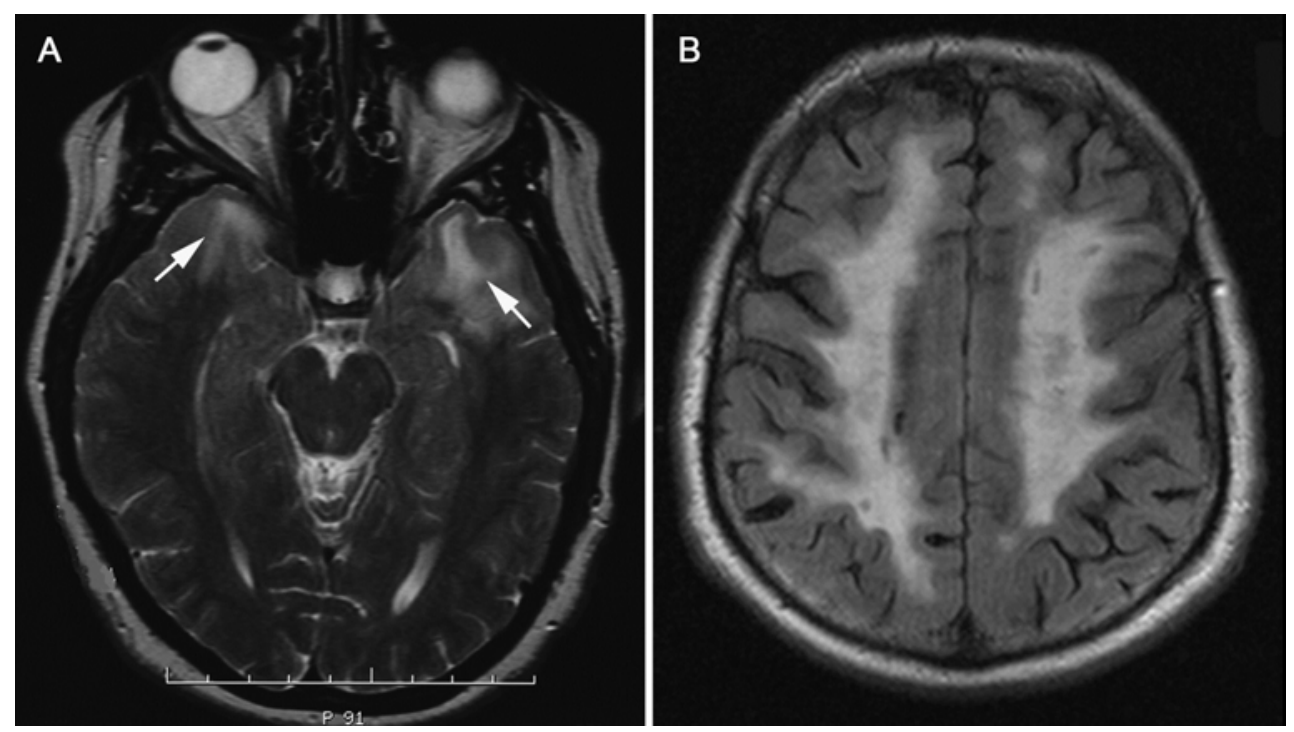

Fig. 4. MRI findings in CADASIL. Hyperintensities in anterior temporal lobes in T2-weighted MRI are characteristic early alterations in CADASIL. A 29-year-old female soon after her first transient ischemic attack. B) At an advanced stage of CADASIL FLAIR MRI shows extensive hyperintensities in the cerebral white matter (leukoaraiosis). Figure 4A is reproduced with permission of Future Neurology (Kalimo et al., 2008)

\subsection{Genetic analysis}

The definite verification of the diagnosis can be done by identifying a pathogenic mutation in the NOTCH3 gene. However, over 200 different mutations in 20 different exons have been reported to cause CADASIL (Tikka et al., 2009, Junna et al. 2011 unpublished). Comprehensive analysis of all these exons is time consuming and costly. Thus, most diagnostic laboratories screen only the exons that according to the previous reports harbour majority of the mutations (Dotti et al., 2005, Escary et al., 2000, Joutel et al., 1997, Kalimo et al., 2002, Opherk et al., 2004). Of the all reported pathogenic NOTCH3 mutations $62 \%$ locate 
in exons 3, 4, 5 and 8 . Furthermore, to obtain $80 \%$ coverage, additional investigation of exons 2, 6, 11 and 18 is required (Tikka et al., 2009). Mutation screening covering the whole region coding for EGF repeats (exons 2-24) is not realistic for all patients and for most laboratories.

\subsection{Skin biopsy}

Given the challenging factors complicating comprehensive genetic analyses it is fortunate that CADASIL is also possible to diagnose by skin biopsy using EM or IHC examination.

\subsubsection{EM analysis}

Although GOM has not been detected in any other disease and the specificity is considered to be $100 \%$ (Ebke et al., 1997, Mayer et al., 1999, Markus et al., 2002, Razvi et al., 2003) the reports on the sensitivity of detecting GOM in skin biopsy of patients with genetically verified CADASIL have been contradictory. Two earlier studies on a smaller number of patients suggested 100\% sensitivity (Ebke et al., 1997, Mayer et al., 1999) in which Ebke et al. analysed one family with 8 patients (mutation not specified) and 5 controls suffering from sporadic leukoencephalopathies and Mayer et al. examined 14 patients (mutation not specified) from three unrelated families. Two more recent papers have reported a low sensitivity: Markus et al. (2002) reported GOM detected only in 8 patients out of 18, thus giving a sensitivity of only $44.4 \%$. Razvi et al. (2003) suspected that the sensitivity might be even lower, although they did not give an exact number. In the latest EM study in a cohort of 131 CADASIL patients and 26 control subjects GOM was detected in all skin biopsies from mutation positive patients and in none of the control biopsies (Tikka et al., 2009). This study was a retrospective investigation of a combined patient material from Finland, Sweden and France comprising 131 patients, from whom both the genetic analysis and EM examination of skin biopsy were available. Skin biopsies from 26 mutation negative members in genetically proven CADASIL families served as controls.

This study showed that EM demonstration of GOM in skin biopsy is a highly reliable and practical method to screen for or even specifically diagnose CADASIL. Furthermore, the intensive search for mutations based on confidence in the diagnostic specificity of GOM resulted in discovery of four novel, previously unreported mutations, among them the first duplication of three codons (Tikka et al., 2009). Thus the detection of GOM in skin biopsies is a highly reliable diagnostic method: in this large cohort the congruence between NOTCH3 mutations and presence of GOM was 100\% (Tikka et al., 2009).

\section{Technical requirements}

When using EM analysis of skin biopsy as a diagnostic method in suspected CADASIL cases, special attention should be paid to the quality and analysis of the skin biopsy. The GOM is best detectable generally from medium sized or small arterioles (usually outer diameter 20-40 $\mu \mathrm{m}$ ) in deep dermis or upper subcutis, but in a few cases GOM has been detected also in veins (Tikka et al. 2009, Fig. 6B) and capillaries (Lewandowska et al., 2010). The detection of fragmented lamina elastica interna as dark blue dots in toluidine blue semithin sections (Figure 5) is a good marker of representative arterioles. Technical factors in the processing of the samples may also influence the result. Since GOM is osmiophilic, the osmium tetroxide treatment should be adjusted such that GOM becomes sufficiently well contrasted. Furthermore, if GOM is not detected in the first vessel 
investigated, other vessels or even repeat biopsies should be examined. Besides, examination should be targeted rather to an artery/arteriole (with multiple layers of VSMCs and inner elastic lamina) than a vein or a capillary, since veins and capillaries are not always GOM positive (Figure 6). Of course, a prerequisite is that the investigator recognizes GOM correctly and distinguishes it from fallacious deposits like small clumps of cell debris or fragmented ECM proteins (Figure 7).

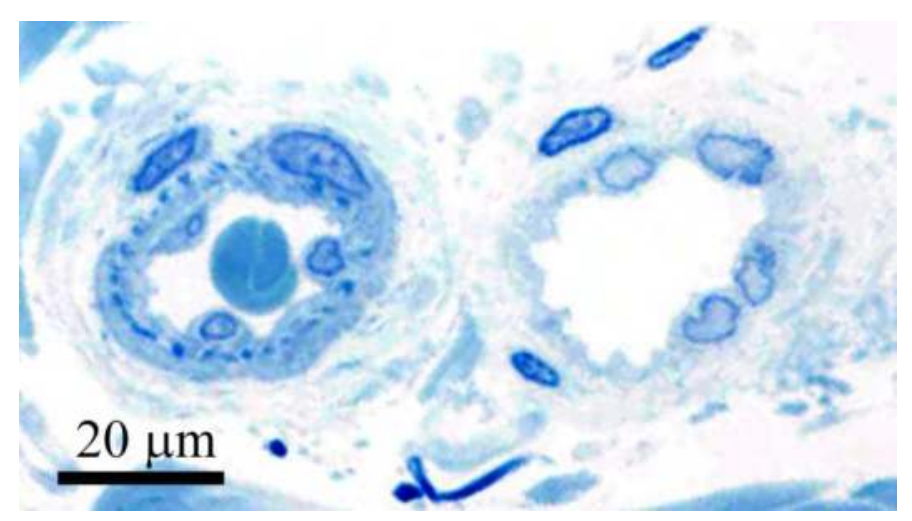

Fig. 5. Small arteriole and vein in skin biopsy. Note the thicker vessel wall and fragmented lamina elastica (dark blue dots beneath endothelial cell layer) in the arteriole. Toluide blue stained semithin epon section of a skin biopsy from CADASIL patient carrying p.Arg133Cys mutation. Figure is reproduced with permission of Brain (Tikka et al., 2009).

\subsubsection{Immunohistochemistry}

IHC showing accumulation of N3ECD in the tunica media of small arteries is another microscopic method to diagnose CADASIL, the availability of IHC being, of course, better than that of EM. Joutel et al. (2001) introduced IHC as a diagnostic tool in CADASIL. In that study they showed in a cohort of 39 patients ( 23 patients, 16 controls) that sensitivity of N3ECD staining was $96 \%$ and specificity $100 \%$. Another study with a cohort of 41 NOTCH3 mutation carriers, 21 controls and 10 hereditary cerebral hemorrhage with amyloidosis-Dutch (HCHWA-D) patients reported sensitivity of $85.4-90.2 \%$ and specificity of $95.2-100 \%$ (Lesnik Oberstein et al., 2003). Both studies reported false negatives which were associated with mutations in exon 11 (Joutel et al., 2001, Lesnik Oberstein et al., 2003). In addition, nonspecific staining is an inherent caveat of IHC producing false positives (Lesnik Oberstein et al., 2003). In the latest immunohistochemical study on 93 skin biopsies from subjects with suspected CADASIL the sensitivity and specificity of the skin biopsies were $97.7 \%$ and $56.5 \%$, respectively though in familial cases the values improved to $100 \%$ and $81.5 \%$ (Ampuero et al., 2009). Specificity was limited in that study by incomplete sequencing of $\mathrm{NOTCH} 3$ (sequenced exons: 2-6, 8, 11, 14, 18, 19, 22 and 23). Although IHC is relatively sensitive and highly specific, given the possibility of false negatives and positives, it should not be used as definitive tool for diagnostics but to help other methods of choice. 

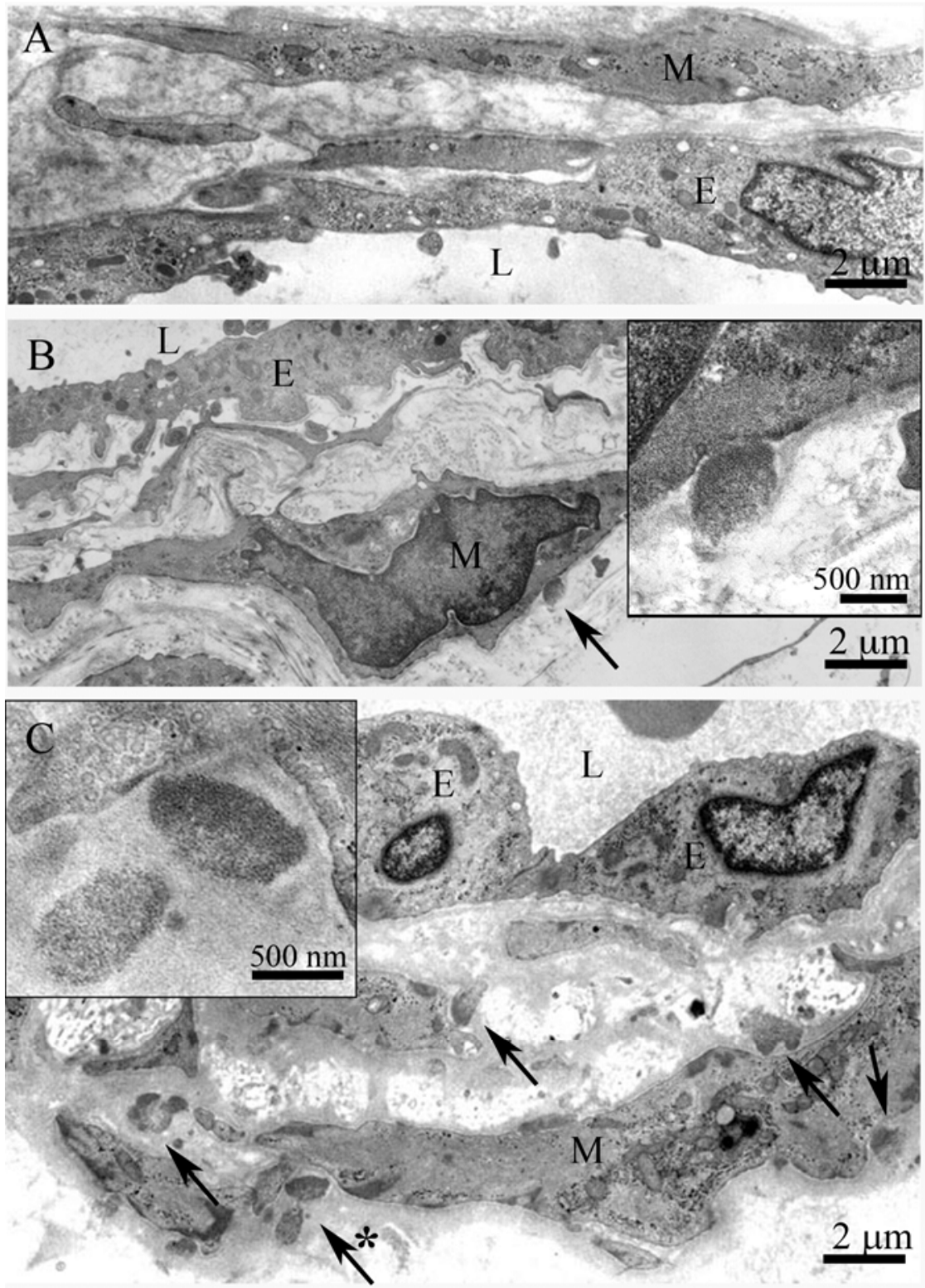

Fig. 6. GOM is usually detected in small arteries or arterioles and sometimes in veins and capillaries. A) The same vein as in figure 5 with no GOM. B) A vein from deep dermis showing one definite GOM (arrow) shown with higher magnification in the inset. C) The same arteriole as in figure 5 with several GOM deposits (five shown with arrows), one marked with asterisk is in the inset with higher magnification. $\mathrm{L}=$ lumen, $\mathrm{E}=$ endothelial cell, $\mathrm{M}=$ vascular smooth muscle cell. Figure is reproduced with permission of Brain (Tikka et al., 2009). 


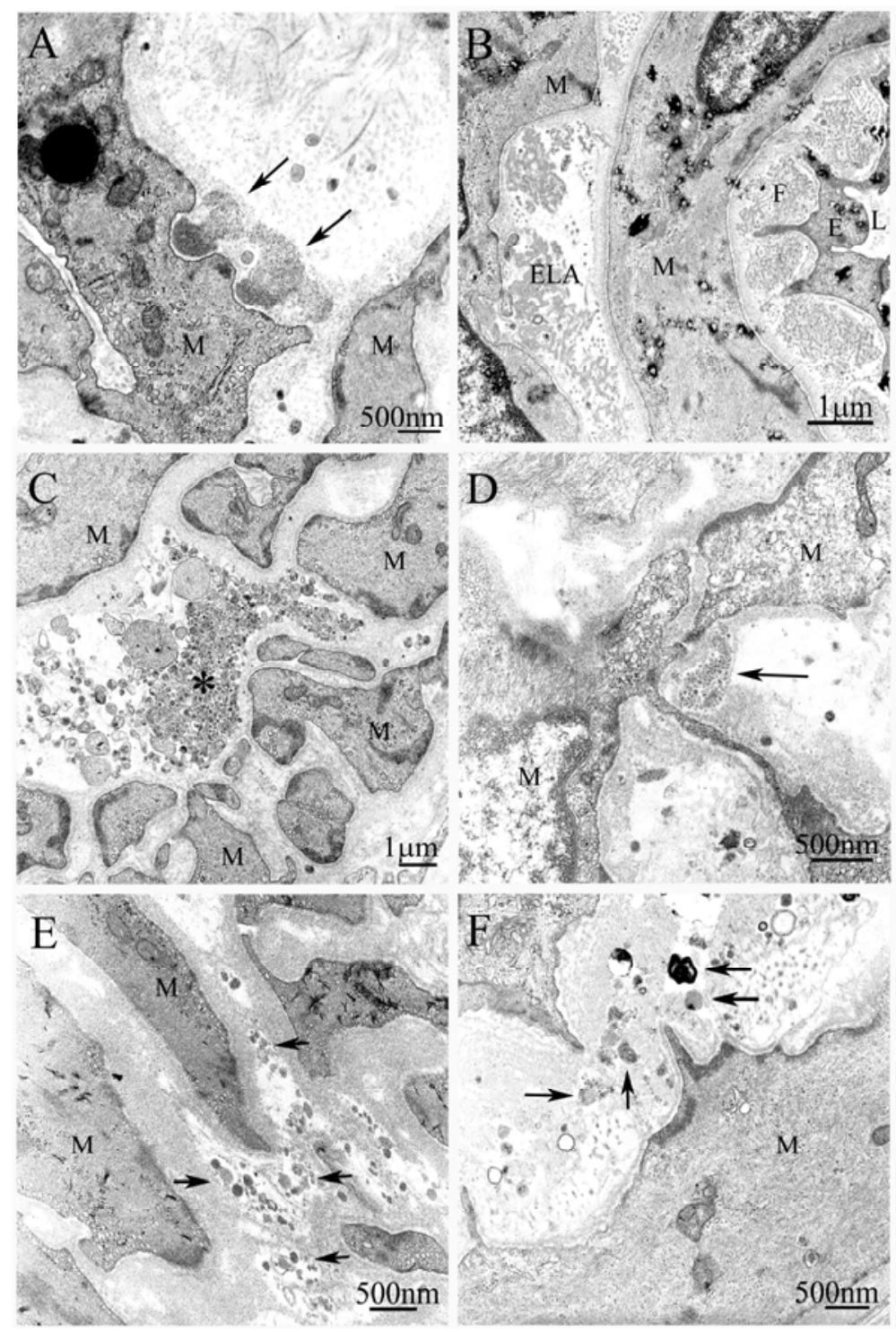

Fig. 7. Fallacious deposits which may lead the electron microscopist astray. A) A true GOM deposits with exceptional mushroom-like form (arrows) in CADASIL skin biopsy. Note the characteristic fine granular appearance of GOM. B) Fragments of elastica interna (ELA) and granular fibrillin network $(\mathrm{F})$ in the widened subendothelial space in skin biopsy of a CADASIL suspect with no GOM and no NOTCH3 mutation. C) Granular debris (asterisk) of unknown origin. D) Similar granular material as in C) (arrow) with misleading location in an indentation of VSMC. E and F) Small clumps of cell debris of different composition (arrows) possibly from degenerated cells. $\mathrm{L}=$ lumen, $\mathrm{E}=$ endothelial cell, $\mathrm{M}=$ vascular smooth muscle cell. Figure is reproduced with permission of Brain (Tikka et al., 2009). 


\subsection{Diagnostic workflow}

What would be the most efficient strategy to confirm the clinical suspicion of CADASIL? Strategy strongly depends on the family history of patient and the mutational background in the population to which the suspected patient belongs. In families with a known mutation, the method of choice is, of course, to analyse directly that mutation. If the patient's population harbours known founder or major mutations, the diagnostic workup is best to begin by first screening for those mutations. In populations with no known founder or other prevailing mutations, screening of the known mutational hot spot region of the NOTCH3 gene should be the first genetic method to search for CADASIL. To obtain $80 \%$ coverage of the reported CADASIL mutations investigation of exons 2-4, 5, 6, 8, 11 and 18 is required (Tikka et al., 2009 Supplement table 1). After these analyses EM or IHC analysis of a skin biopsy for detection of GOM or accumulation of N3ECD is highly recommended. Similar approach has been suggested by Peters et al. (2005). Mutation screening covering the whole region coding for EGF repeats (exons 2-24) is not realistic for all suspected patients and for most diagnostic laboratories.

N3ECD the immunostaining has been found reliable method in cases with at least a fair amount of accumulated N3ECD (Joutel et al., 2001). However, if only a small amount of the N3ECD has accumulated, e.g. at the early stage of the disease, ultrastructural resolution and characteristic appearance of GOM most likely make the EM analysis more reliable. We have detected GOM even in patients below the age of 20 years (Figure 3C). Besides, nonspecific staining producing false positives is an inherent caveat of immunohistochemistry (Lesnik Oberstein et al., 2003), which may cause problems also in CADASIL cases with only small amounts of N3ECD giving rise to false negatives. Moreover, EM examination provides also information about other pathological changes in the arterial wall, such as those due to hypertension, ageing and possibly even other hereditary arteriopathies (Brulin et al., 2002, Ruchoux et al., 2000, Ruchoux et al., 2002). The Swedish family with multi-infarct dementia was previously thought to be the first published pedigree with CADASIL (Sourander and Walinder, 1977). The absence of GOM in the arteries was an important piece of evidence in addition to the negative genetic analyses in the demonstration that this family suffers from another hereditary vascular dementia (Low et al., 2007). On the other hand, another cerebral small vessels disease caused by a novel type of pathogenic mutation (p.Leu1515Pro) in the exon 25 of NOTCH3 outside the EGF like repeat rich domain, results in constitutively active NOTCH3 receptor (Fouillade et al., 2008). This leads to increased signaling in a ligandindependent fashion, possibly due to destabilization of the NOTCH3 heterodimer. Remarkably, in this single patient reported there is no deposition of N3ECD and GOM on VSMCs.

\section{Conclusion}

The strategy of the CADASIL workup should be based on logical evaluation of clinical findings, family history as well as on both genetic and morphological methods available. Demonstration of a known pathogenic mutation provides indisputable evidence for the disease and gives a practical tool to clarify genetic counselling in the family. In those cases, in which the mutation is not easy to identify or genetic analysis is not available, skin biopsy is easy to perform. IHC showing accumulation of N3ECD can also be used as a supportive method in diagnostic process although it should not be used as only method. Detection of GOM by EM should be preferable method when analysing skin biopsies given its high specificity and sensitivity. Neither is it time consuming nor excessively expensive. Importantly, it is invaluable in guiding, how far one should proceed with the genetic analyses. 


\section{Acknowledgment}

For their skilful ultrastructural techniques we thank in Finland Ms. Virpi Myllys in Turku and Ms. Svetlana Zueva in Helsinki; in Sweden Ms. Madeleine Jarild in Uppsala and in France Ms. Sylvie Limol and Ms. Nathalie Goethink in Lille and Ms. Fabienne Arcanger in Tours.

\section{References}

Ampuero I, Alegre-Abarrategui J, Rodal I, Espana A, Ros R, Sendon JL, et al. On the diagnosis of CADASIL. J Alzheimers Dis 2009; 17: 787-94

Baudrimont M, Dubas F, Joutel A, Tournier-Lasserve E, Bousser MG. Autosomal dominant leukoencephalopathy and subcortical ischemic stroke. A clinicopathological study. Stroke 1993; 24: 122-5

Brulin P, Godfraind C, Leteurtre E, Ruchoux MM. Morphometric analysis of ultrastructural vascular changes in CADASIL: Analysis of 50 skin biopsy specimens and pathogenic implications. Acta Neuropathol 2002; 104: 241-8

Chabriat H, Levy C, Taillia H, Iba-Zizen MT, Vahedi K, Joutel A, et al. Patterns of MRI lesions in CADASIL. Neurology 1998; 51: 452-7

Dotti MT, Federico A, Mazzei R, Bianchi S, Scali O, Conforti FL, et al. The spectrum of Notch3 mutations in 28 italian CADASIL families. J Neurol Neurosurg Psychiatry 2005; 76: 736-8

Ebke M, Dichgans M, Bergmann M, Voelter HU, Rieger P, Gasser T, et al. CADASIL: Skin biopsy allows diagnosis in early stages. Acta Neurol Scand 1997; 95: 351-7

Escary JL, Cecillon M, Maciazek J, Lathrop M, Tournier-Lasserve E, Joutel A. Evaluation of DHPLC analysis in mutational scanning of Notch3, a gene with a high G-C content. Hum Mutat 2000; 16: 518-26

Fouillade C, Chabriat H, Riant F, Mine M, Arnoud M, Magy L, et al. Activating NOTCH3 mutation in a patient with small-vessel-disease of the brain. Hum Mutat 2008; 29: 452

Granild-Jensen J, Jensen UB, Schwartz M, Hansen US. Cerebral autosomal dominant arteriopathy with subcortical infarcts and leukoencephalopathy resulting in stroke in an 11-year-old male. Dev Med Child Neurol 2009; 51: 754-7

Ishiko A, Shimizu A, Nagata E, Takahashi K, Tabira T, Suzuki N. Notch3 ectodomain is a major component of granular osmiophilic material (GOM) in CADASIL. Acta Neuropathol (Berl) 2006; 112: 333-9

Joutel A, Favrole P, Labauge P, Chabriat H, Lescoat C, Andreux F, et al. Skin biopsy immunostaining with a Notch3 monoclonal antibody for CADASIL diagnosis. Lancet 2001; 358: 2049-51

Joutel A, Andreux F, Gaulis S, Domenga V, Cecillon M, Battail N, et al. The ectodomain of the Notch3 receptor accumulates within the cerebrovasculature of CADASIL patients. J Clin Invest 2000; 105: 597-605

Joutel A, Vahedi K, Corpechot C, Troesch A, Chabriat H, Vayssiere C, et al. Strong clustering and stereotyped nature of Notch3 mutations in CADASIL patients. Lancet 1997; 350: 1511-5

Joutel A, Corpechot C, Ducros A, Vahedi K, Chabriat H, Mouton P, et al. Notch3 mutations in CADASIL, a hereditary adult-onset condition causing stroke and dementia. Nature 1996; 383: 707-10

Kalimo H, Miao Q, Tikka S, Mykkanen K, Junna M, Roine S, et al. CADASIL: The most common hereditary subcortical vascular dementia. Future Neurology 2008; 3: 683

Kalimo H, Ruchoux MM, Viitanen M, Kalaria RN. CADASIL: A common form of hereditary arteriopathy causing brain infarcts and dementia. Brain Pathol 2002; 12: 371-84 
Lesnik Oberstein SA, van Duinen SG, van den Boom R, Maat-Schieman ML, van Buchem $\mathrm{MA}$, van Houwelingen $\mathrm{HC}$, et al. Evaluation of diagnostic NOTCH3 immunostaining in CADASIL. Acta Neuropathol 2003; 106: 107-11

Lewandowska E, Szpak GM, Wierzba-Bobrowicz T, Modzelewska J, Stepien T, Pasennik E, et al. Capillary vessel wall in CADASIL angiopathy. Folia Neuropathol 2010; 48: 104-15

Low WC, Junna M, Borjesson-Hanson A, Morris CM, Moss TH, Stevens DL, et al. Hereditary multi-infarct dementia of the swedish type is a novel disorder different from NOTCH3 causing CADASIL. Brain 2007; 130: 357-67

Markus HS, Martin RJ, Simpson MA, Dong YB, Ali N, Crosby AH, et al. Diagnostic strategies in CADASIL. Neurology 2002; 59: 1134-8

Mayer M, Straube A, Bruening R, Uttner I, Pongratz D, Gasser T, et al. Muscle and skin biopsies are a sensitive diagnostic tool in the diagnosis of CADASIL. J Neurol 1999; 246: 526-32

Miao Q, Paloneva T, Tuominen S, Poyhonen M, Tuisku S, Viitanen M, et al. Fibrosis and stenosis of the long penetrating cerebral arteries: The cause of the white matter pathology in cerebral autosomal dominant arteriopathy with subcortical infarcts and leukoencephalopathy. Brain Pathol 2004; 14: 358-64

Opherk C, Peters N, Herzog J, Luedtke R, Dichgans M. Long-term prognosis and causes of death in CADASIL: A retrospective study in 411 patients. Brain 2004; 127: 2533-9

O'Sullivan M, Jarosz JM, Martin RJ, Deasy N, Powell JF, Markus HS. MRI hyperintensities of the temporal lobe and external capsule in patients with CADASIL. Neurology 2001; 56: 628-34

Peters N, Opherk C, Bergmann T, Castro M, Herzog J, Dichgans M. Spectrum of mutations in biopsy-proven CADASIL: Implications for diagnostic strategies. Arch Neurol 2005; 62: 1091-4

Ragno M, Tournier-Lasserve E, Fiori MG, Manca A, Patrosso MC, Ferlini A, et al. An italian kindred with cerebral autosomal dominant arteriopathy with subcortical infarcts and leukoencephalopathy (CADASIL). Ann Neurol 1995; 38: 231-6

Razvi SS, Davidson R, Bone I, Muir KW. Diagnostic strategies in CADASIL. Neurology 2003; 60: 2019,20; author reply 2020

Ruchoux MM, Brulin P, Brillault J, Dehouck MP, Cecchelli R, Bataillard M. Lessons from CADASIL. Ann N Y Acad Sci 2002; 977: 224-31

Ruchoux MM, Brulin P, Leteurtre E, Maurage CA. Skin biopsy value and leukoaraiosis. Ann N Y Acad Sci 2000; 903: 285-92

Ruchoux MM, Maurage CA. CADASIL: Cerebral autosomal dominant arteriopathy with subcortical infarcts and leukoencephalopathy. J Neuropathol Exp Neurol 1997; 56: 947-64

Ruchoux MM, Guerouaou D, Vandenhaute B, Pruvo JP, Vermersch P, Leys D. Systemic vascular smooth muscle cell impairment in cerebral autosomal dominant arteriopathy with subcortical infarcts and leukoencephalopathy. Acta Neuropathol (Berl) 1995; 89: 500-12

Ruchoux MM, Chabriat H, Bousser MG, Baudrimont M, Tournier-Lasserve E. Presence of ultrastructural arterial lesions in muscle and skin vessels of patients with CADASIL. Stroke 1994; 25: 2291-2

Sourander P, Walinder J. Hereditary multi-infarct dementia. morphological and clinical studies of a new disease. Acta Neuropathol 1977; 39: 247-54

Tikka S, Mykkanen K, Ruchoux MM, Bergholm R, Junna M, Poyhonen M, et al. Congruence between NOTCH3 mutations and GOM in 131 CADASIL patients. Brain 2009; 132: 933-9 


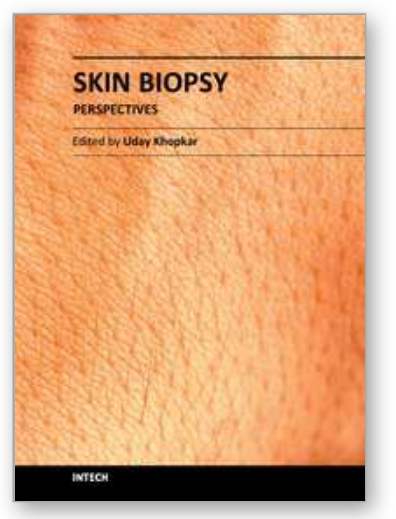

\author{
Skin Biopsy - Perspectives \\ Edited by Dr. Uday Khopkar
}

ISBN 978-953-307-290-6

Hard cover, 336 pages

Publisher InTech

Published online 02, November, 2011

Published in print edition November, 2011

Skin Biopsy - Perspectives is a comprehensive compilation of articles that relate to the technique and applications of skin biopsy in diagnosing skin diseases. While there have been numerous treatises to date on the interpretation or description of skin biopsy findings in various skin diseases, books dedicated entirely to perfecting the technique of skin biopsy have been few and far between. This book is an attempt to bridge this gap. Though the emphasis of this book is on use of this technique in skin diseases in humans, a few articles on skin biopsy in animals have been included to acquaint the reader to the interrelationship of various scientific disciplines. All aspects of the procedure of skin biopsy have been adequately dealt with so as to improve biopsy outcomes for patients, which is the ultimate goal of this work.

\title{
How to reference
}

In order to correctly reference this scholarly work, feel free to copy and paste the following:

Saara Tikka, Kati Mykkänen, Maija Junna, Robert Bergholm, Minna Pöyhönen, Marc Baumann, Matti Viitanen and Hannu Kalimo (2011). Diagnosing Vascular Dementia by Skin Biopsy - Uniqueness of CADASIL, Skin Biopsy - Perspectives, Dr. Uday Khopkar (Ed.), ISBN: 978-953-307-290-6, InTech, Available from: http://www.intechopen.com/books/skin-biopsy-perspectives/diagnosing-vascular-dementia-by-skin-biopsyuniqueness-of-cadasil

\section{INTECH}

open science | open minds

\author{
InTech Europe \\ University Campus STeP Ri \\ Slavka Krautzeka 83/A \\ 51000 Rijeka, Croatia \\ Phone: +385 (51) 770447 \\ Fax: +385 (51) 686166 \\ www.intechopen.com
}

\author{
InTech China \\ Unit 405, Office Block, Hotel Equatorial Shanghai \\ No.65, Yan An Road (West), Shanghai, 200040, China \\ 中国上海市延安西路65号上海国际贵都大饭店办公楼 405 单元 \\ Phone: +86-21-62489820 \\ Fax: $+86-21-62489821$
}


(C) 2011 The Author(s). Licensee IntechOpen. This is an open access article distributed under the terms of the Creative Commons Attribution 3.0 License, which permits unrestricted use, distribution, and reproduction in any medium, provided the original work is properly cited. 